\title{
The 21-gene recurrence score complements IBTR! Estimates in early-stage, hormone receptor-positive, HER2-normal, lymph node-negative breast cancer
}

\author{
Nikhil G Thaker ${ }^{1}$, Karen E Hoffman ${ }^{1}$, Michael C Stauder ${ }^{1}$, Simona F Shaitelman ${ }^{1}$, Eric A Strom ${ }^{1}$, Welela Tereffe ${ }^{1}$, \\ Benjamin D Smith ${ }^{1}$, George H Perkins', Lei Huo², Mark F Munsell ${ }^{3}$, Lajos Pusztai ${ }^{4}$, Thomas A Buchholz ${ }^{1}$ \\ and Wendy A Woodward ${ }^{\text {* }}$
}

\begin{abstract}
Clinicians have traditionally used clinicopathological (CP) factors to determine locoregional recurrence (LR) risk of breast cancer and have generated the IBTR! nomogram to predict the risk of ipsilateral breast tumor recurrence (IBTR). The 21-gene recurrence score (RS) assay was recently correlated with $L R$ in retrospective studies. The objective of this study was to examine the relationship between the RS and IBTR!. CP characteristics of 308 consecutive patients who underwent RS testing at our institution were examined. IBTR! was used to estimate the risk of 10-year IBTR. Descriptive statistics were used to compare the RS with the estimated IBTR!. Given a low event rate in this cohort, actual IBTR rates were not reported. Most patients had stage I/II (98\%) and grade I/II (77\%) disease. Median age was 54 years (range, 30-78). Median IBTR! without radiation therapy was 10\% (mean, 12\% [range, 4-43\%]). RS was low $(<18)$, intermediate (18-30), and high ( $>30)$ in 52\% ( $n=160), 40 \%(n=123)$, and $8 \%(n=25)$ patients. Overall, IBTR! did not correlate with RS $(P=.77)$. We saw no correlation between RS and IBTR! in patients with less than $(P=.32)$ or greater than $(P=.48)$ a $10 \%$ risk of IBTR. Interestingly, Ki-67 expression correlated with both IBTR! $(P=.019)$ and the RS $(P=.002)$. Further study is warranted to determine if the RS can provide complementary biological information to CP factors in estimating the risk of LR. Prospective studies evaluating this association may potentially allow for individualized treatment decisions.
\end{abstract}

Keywords: Oncotype Dx; 21-gene recurrence score; Molecular profiling; Ipsilateral breast tumor recurrence; IBTR!; Local recurrence

\section{Introduction}

Local treatment decisions for patients with breast cancer are traditionally based on conventional clinicopathological (CP) factors such as age, tumor size and grade, TNM stage, margin status, lymphovascular invasion (LVSI), chemotherapy use, and hormone therapy use. A web-based predictive nomogram IBTR! (IBTR Version 2 0 Breast Cancer Model) is commonly used to estimate a patient's risk of ipsilateral breast tumor recurrence (IBTR) according to several well-established CP factors (Sanghani et al. 2007; Sanghani et al. 2010). However,

\footnotetext{
* Correspondence: wwoodward@mdanderson.org

'Department of Radiation Oncology, Unit 1202, The University of Texas MD Anderson Cancer Center, 1515 Holcombe Boulevard, Houston, TX 77030, USA Full list of author information is available at the end of the article
}

breast cancer is actually a heterogeneous group of diseases, and definitive treatment options may vary by molecular subtype.

Physicians have incorporated several molecular profiling tools into breast cancer clinics (Paik et al. 2004; Goldstein et al. 2008; Tang et al. 2011). The most widely used gene expression profiling tool is the 21-gene Oncotype Dx Recurrence Score (RS) assay (OncotypeDX; GenomicHealth Inc., Redwood City, Calif.), which is used to estimate the risk of 10-year distant recurrence (DR) and predict the likelihood of benefit of adjuvant chemotherapy for hormone receptor (HR)-positive, node-negative, tamoxifen-treated breast cancer (Paik et al. 2004; Paik et al. 2006). Both the National Comprehensive Cancer Network and American Society of 
Clinical Oncology consider the 21-gene RS assay an option for evaluating early-stage, HR-positive, lymph node-negative breast cancer (Network 2013; Harris et al. 2007).

Despite rapid integration of these genetic tools to assess the need for systemic management of breast cancer, their use in estimating the risk of locoregional recurrence (LR), which includes IBTR, chest wall recurrence, and regional nodal recurrence, has remained underdeveloped. Recent studies suggest that molecular profiling tools designed to assess the risk of DR, such as the RS, also predict increased risk of LR (Haffty 2002; Voduc et al. 2010; Mamounas et al. 2010; Taghian et al. 2004; Wapnir et al. 2008; Kirk 2010; Cheng et al. 2006; Nuyten et al. 2006). However, detailed information about the overlap between molecular-based risk stratification and standard CP factors that are known causes of LR is unavailable. Elucidation of this relationship would be useful, because clinicians have traditionally utilized CP factors to predict the risk of IBTR, and molecular tools hold the future promise for predicting the risk of LR. The objective of the present study was to examine the relationship between the 21-gene RS and the estimated risk of IBTR based on CP features in breast cancer patients primarily at intermediate-risk for IBTR, for whom clinical uncertainty exists as to the need for therapeutic escalation versus de-escalation. We sought to identify clinical scenarios in which the RS may complement CP information when making individualized local management decisions.

\section{Materials and methods \\ Study population}

Patients diagnosed with breast cancer who underwent the 21-gene RS assay testing as part of routine care or in the context of the National Cancer Institute's Trial Assigning IndividuaLized Options for Treatment (TAILORx) trial from December 2004 to November 2008 were included in this study. In the TAILORx trial, researchers are evaluating whether hormone therapy alone or with combination chemotherapy is better for women with node-negative, estrogen receptor (ER)-positive breast cancer having an RS of 11-25 (Hormone Therapy With or Without Combination Chemotherapy in Treating Women Who Have Undergone Surgery for Node-Negative Breast Cancer (The TAILORx Trial) 2013). Patients who were clinically node-negative but pathologically node-positive during this time period were also included in this cohort as part of routine care at this institution.

Demographic and CP data on the study patients were abstracted from a prospectively maintained clinical database according to an MD Anderson Institutional Review Board-approved protocol. All pathological information, including histological type, tumor grade, tumor size, nodal status, and tumor marker expression were reviewed by breast pathologists. Ki-67 expression was measured using immunohistochemistry as part of the routine pathological evaluation and was reported as the percentage of Ki-67 positive nuclei in invasive neoplastic cells. Ki-67 expression information was available for 116 of 308 patients.

\section{The 21-gene RS}

Tumor samples obtained from the study patients were submitted for the 21-gene RS assay (OncotypeDX; GenomicHealth Inc., Redwood City, Calif.). This profiling tool measures the expression of 16 cancer-related and 5 control genes in paraffin-embedded breast tumor samples using a reverse transcriptase-polymerase chain reaction assay as described previously (Paik et al. 2004). Based on the level of expression of each gene, a continuous variable known as the RS is calculated, ranging from 0 to 100 . This score can be used to estimate the risk of 10-year DR and predict the likelihood of adjuvant chemotherapy benefit in patients with node-negative, HR-positive, tamoxifen-treated breast cancer (Paik et al. 2004; Paik et al. 2006).

\section{IBTR! nomogram}

The IBTR! nomogram (version 2.0; Breast Cancer Model) is a web-based predictive tool that uses literature-derived relative risk ratios for seven $\mathrm{CP}$ tumor factors (age, tumor size and grade, margin status, LVSI, and chemotherapy and hormone therapy use) to predict the 10-year risk of IBTR with and without radiation therapy (RT) (Sanghani et al. 2010). The 10-year estimated risk of IBTR was calculated and recorded for each patient using IBTR! (IBTR Version 20 Breast Cancer Model; Sanghani et al. 2010). IBTR! without RT was used in this study (Sanghani et al. 2010).

\section{Statistical analysis}

Descriptive statistics were used to compare the RS with the estimated 10-year risk of IBTR!. Analysis of variance with Tukey's adjustment for multiple comparisons was used to compare scores among various factors. Correlations among RS, age, and Ki-67 expression were also evaluated. Spearman's rank correlation coefficient was used to estimate the strength of association between RS and IBTR!, RS and Ki-67 expression, IBTR! and Ki-67 expression, and IBTR! and age at diagnosis. Ki-67 was compared as a categorical variable and as a continuous variable. Stratification according to type of local treatment was also include for the IBTR! and RS comparisons. All significance tests were two-tailed, with $P$ values less than .05 considered significant. Analyses were performed using the SAS software program (version 9.3 for Windows; SAS Institute Inc., Cary, N.C.). Actuarial LR, 
IBTR!, and survival results were not reported because of a short median follow-up duration and low event rate.

\section{Results}

\section{Patient and tumor characteristics}

We identified 308 consecutive patients who underwent the RS assay (Table 1). Their median age was 54 years (range, 30-78 years). Ninety-nine percent of patients $(\mathrm{N}=305)$ had stage I/II disease, and $77 \%(\mathrm{~N}=238)$ had grade I/II tumors. Sixty-six percent $(\mathrm{N}=203)$ underwent breast-conserving surgery (BCS; $6 \%[\mathrm{~N}=19]$ alone and $60 \%[\mathrm{~N}=184]$ with $\mathrm{RT})$, and $34 \%(\mathrm{~N}=105)$ underwent mastectomy $(31 \%[\mathrm{~N}=96]$ alone and $3 \%[\mathrm{~N}=9]$ with RT). We classified 52\% $(\mathrm{N}=160), 40 \%(\mathrm{~N}=123)$, and $8 \%(\mathrm{~N}=25)$ of the patients into the low-risk $(<18)$, intermediate-risk (18-30), and high-risk (>30) categories as defined by the assay. Using the TAILORx risk groups, we classified $69 \%(\mathrm{~N}=212)$ of the patients into the intermediate-risk group (RS of 11-25).

\section{Correlation of CP factors with 21-gene RS}

High (>20\%) Ki-67 expression (Delpech et al. 2012; Kilickap et al. 2014), high tumor grade, LVSI, and chemotherapy use was seen in a greater proportion of the high RS group than in the low and intermediate RS groups. However, we saw no differences in pathological stage, type of surgery (BCS versus mastectomy), number of positive lymph nodes, or tumor size among the risk groups (Table 1). When we stratified the $\mathrm{CP}$ factors by type of surgery (BCS versus mastectomy), we observed no significant differences according to RS risk group, tumor grade, LVSI, or chemotherapy use. However, patients who underwent mastectomy tended to have larger primary tumors $(P=.0069)$ and more hormone therapy use $(P=.0406)$ than did patients who underwent BCS.

\section{Correlation of IBTR! score and RS}

The median IBTR! score in all 308 patients was 10\% (mean, 12\% [range, 4-43\%]). As expected, young age $(P<.001)$ and high tumor grade associated most strongly with higher IBTR! scores (Figure 1$)(P<.001)$. Interestingly, Ki-67 expression correlated with both IBTR! and RS (Figure 2A, B). However, IBTR! score did not correlate with RS $(P=.7655, \mathrm{r}=.017)$ (Figure 3A). Among patients with less than a $10 \%$ risk of IBTR $(n=132), 50 \%$ had low RSs, whereas the remaining $50 \%$ had intermediate or high RSs (Figure 3B). Likewise, we did not observe significant correlation of IBTR! score with RS at higher IBTR! scores (Figure 3C). Additionally, there was no significant difference in the distribution of RS when IBTR was low $(<10 \%)$ or high $(>10 \%)$ (Figure 3D). Stratification of IBTR! scores according to TAILORx risk groups ( $R S<=25$ and $\mathrm{RS}>25)$ further emphasized the wide variation in IBTR! score with either a high or low to intermediate RS and no correlation (Figure 3E).

We then estimated the IBTR! scores for each of the four treatment groups, based upon the actual treatments received (BCS, breast conserving therapy $[\mathrm{BCT}]$, Mastectomy, and Mastectomy and postoperative radiation therapy [PORT]). Previous comparisons utilized the IBTR! without RT for all patients to provide a more homogeneous IBTR! score estimate. These comparisons once again confirmed that patients at high or low risk for IBTR! based on CP factors and treatment (Figure 4A) still had large variations in RS (Figure 4B), emphasizing the need to evaluate molecular profiles in homogeneously treated populations of breast cancer patients. The distribution in BCS and mastectomy subgroups are wide in both the IBTR! and RS stratifications. However, the deviation is less in the groups that have undergone RT.

\section{Discussion}

Physicians have traditionally based LR treatment decisions for patients with early-stage breast cancer on $\mathrm{CP}$ characteristics such as tumor size and grade, margin status, pathological nodal status, and LVSI. However, breast cancer represents a heterogeneous group of diseases, and additional biological information about tumor gene expression may assist in local therapy decisions. Despite major progress in identifying genomic profiles associated with risk of DR and benefit of chemotherapy, only recently have studies demonstrated that the 21-gene RS may help estimate the risk of LR (Voduc et al. 2010; Mamounas et al. 2010). To date, though, researchers have yet to explicitly determine how many patients with seemingly innocuous breast cancer in terms of LR estimates may have high RSs or vice versa. The present study demonstrated minimal redundancy between $\mathrm{CP}$ risk factors and RS, suggesting that the 21-gene RS adds complementary biological information to the $\mathrm{CP}$ factors traditionally used to assess risk of IBTR.

Several promising studies recently examined the relationship between the RS and LR (Table 2). Mamounas et al. (Mamounas et al. 2010) initially examined the correlation between the 21-gene RS and LR risk in patients with node-negative, ER-positive breast cancer treated with breast conservation therapy (BCT) or mastectomy without RT. The authors concluded that RS was highly associated with risk of LR in patients with tamoxifen-treated, placebo-treated, or chemotherapy- plus tamoxifen-treated disease. RS, age, and initial treatment type were independent predictors of LR. However, the relationship was more complex in patients who received RT, suggesting that the effectiveness of RT increases as the RS increases. Solin et al. reported more conflicting results (Solin et al. 2012). They demonstrated that neither biological subtype nor 21-gene RS were associated with LR, although RS was a 
Table 1 Patient demographics and characteristics

\begin{tabular}{|c|c|c|c|c|c|}
\hline \multirow[b]{2}{*}{ Variable } & \multirow[b]{2}{*}{$\begin{array}{l}\text { All patients, } \\
\mathrm{N}=308\end{array}$} & \multicolumn{3}{|c|}{ No. of patients (\%) } & \multirow[b]{2}{*}{$P$-value } \\
\hline & & $\begin{array}{l}\text { Low RS }(<18), \\
N=160\end{array}$ & $\begin{array}{l}\text { Intermediate RS (18-30), } \\
\mathrm{N}=123\end{array}$ & $\begin{array}{l}\text { High RS (>30), } \\
\mathrm{N}=25\end{array}$ & \\
\hline Median age at diagnosis, y (range) & $54(30-78)$ & $53(31-78)$ & $55(30-73)$ & $59(40-75)$ & NS \\
\hline Frequency by race & & & & & NS \\
\hline Asian/Pacific Islander & $10(3)$ & $7(4)$ & $2(2)$ & $1(4)$ & \\
\hline Black & $16(5)$ & $7(4)$ & $7(6)$ & $2(8)$ & \\
\hline Native American & $1(0.3)$ & $1(1)$ & $0(0)$ & $0(0)$ & \\
\hline Other & $2(1)$ & $0(0)$ & $1(1)$ & $1(4)$ & \\
\hline Spanish/Hispanic & $42(14)$ & $24(15)$ & $14(11)$ & $4(16)$ & \\
\hline White & $237(77)$ & $121(76)$ & $99(81)$ & $17(68)$ & \\
\hline Type of surgery & & & & & NS \\
\hline BCT & $203(66)$ & $100(63)$ & $85(69)$ & $18(72)$ & \\
\hline Mastectomy & $105(34)$ & $60(38)$ & $38(31)$ & $7(28)$ & \\
\hline Histology & & & & & .0225 \\
\hline Invasive ductal & $214(70)$ & $100(63)$ & $91(74)$ & $23(92)$ & \\
\hline Invasive lobular & $37(12)$ & $24(15)$ & $13(11)$ & $0(0)$ & \\
\hline Other & $57(19)$ & $36(23)$ & $19(15)$ & $2(8)$ & \\
\hline Pathological stage & & & & & NS \\
\hline 0 & $3(1)$ & $3(2)$ & $0(0)$ & $0(0)$ & \\
\hline I & $243(79)$ & $127(79)$ & $97(79)$ & $19(76)$ & \\
\hline$\| \mathrm{A}$ & $52(17)$ & $25(16)$ & $21(17)$ & $6(24)$ & \\
\hline$\| \mathrm{B}$ & $7(2)$ & $3(2)$ & $4(3)$ & $0(0)$ & \\
\hline$\| I I A$ & $1(0.3)$ & $1(1)$ & $0(0)$ & $0(0)$ & \\
\hline IIIB & $1(0.3)$ & $1(1)$ & $0(0)$ & $0(0)$ & \\
\hline No. of positive lymph nodes & & & & & NS \\
\hline 0 & $286(93)$ & $152(95)$ & $110(89)$ & $24(96)$ & \\
\hline 1 & $15(5)$ & $4(3)$ & $10(8)$ & $1(4)$ & \\
\hline 2 & $2(1)$ & $0(0)$ & $2(2)$ & $0(0)$ & \\
\hline 3 & $1(0.3)$ & $1(1)$ & $0(0)$ & $0(0)$ & \\
\hline 4 & $1(0.3)$ & $1(1)$ & $0(0)$ & $0(0)$ & \\
\hline Tumor grade & & & & & $<.0001$ \\
\hline I & $45(15)$ & $31(19)$ & $14(11)$ & $0(0)$ & \\
\hline$\|$ & $193(63)$ & $107(67)$ & $80(65)$ & $6(24)$ & \\
\hline III & $70(23)$ & $22(14)$ & $29(24)$ & $19(76)$ & \\
\hline PR status & & & & & $<.0001$ \\
\hline Positive & $272(88)$ & $145(91)$ & $112(91)$ & $15(60)$ & \\
\hline Negative & $31(10)$ & $10(6)$ & $11(89)$ & $10(40)$ & \\
\hline Unknown & $5(2)$ & $5(3)$ & $0(0)$ & $0(0)$ & \\
\hline Ki-67 expression & & & & & .0024 \\
\hline High (>20\%) & $27(9)$ & $9(6)$ & $11(9)$ & $7(28)$ & \\
\hline Intermediate (10-20\%) & $41(13)$ & $23(14)$ & $16(13)$ & $2(8)$ & \\
\hline Low $(<10 \%)$ & $48(16)$ & $29(18)$ & $19(16)$ & $0(0)$ & \\
\hline Not measured & $195(63)$ & $99(62)$ & $77(63)$ & $16(64)$ & \\
\hline
\end{tabular}


Table 1 Patient demographics and characteristics (Continued)

\begin{tabular}{|c|c|c|c|c|c|}
\hline Vascular invasion & & & & & .0162 \\
\hline Positive & $41(13)$ & $16(10)$ & $17(14)$ & $8(32)$ & \\
\hline Negative & $267(87)$ & $144(90)$ & $106(86)$ & $17(68)$ & \\
\hline Tumor size & & & & & NS \\
\hline$<2 \mathrm{~cm}$ & $230(75)$ & $119(75)$ & $93(76)$ & $18(72)$ & \\
\hline$\geq 2 \mathrm{~cm}$ & $73(24)$ & $38(24)$ & $28(23)$ & $7(28)$ & \\
\hline Chemotherapy use & & & & & $<.0001$ \\
\hline Yes & $81(26)$ & $15(9)$ & $47(38)$ & $19(76)$ & \\
\hline No & $227(74)$ & $145(91)$ & $76(62)$ & $6(24)$ & \\
\hline Hormone therapy use & & & & & .0220 \\
\hline Yes & $264(86)$ & $145(91)$ & $100(81)$ & $19(76)$ & \\
\hline No & $44(15)$ & $15(9)$ & $23(19)$ & $6(24)$ & \\
\hline
\end{tabular}

Abbreviations: $B C T$ breast conserving therapy, NS not significant, $P R$ progesterone receptor.

significant predictor as a continuous variable in patients with HR-positive tumors. The authors concluded that neither biological subtype nor 21-gene RS should preclude BCT with RT.

More recently, several groups examined the prognostic and predictive ability of the 21-gene RS assay in other subgroups of breast cancer patients. For example, Mamounas et al. (Mamounas et al. 2013) reported a significant association between RS and LR after BCT or mastectomy in patients with at least four positive nodes and a nonsignificant trend in patients with one to three positive nodes. Solin et al. (Solin et al. 2013) modified the 21-gene RS assay to create a ductal carcinoma in situ (DCIS) RS, incorporating expression data on seven cancer-related genes and five reference genes. They found that the continuous DCIS RS was significantly associated with the risk of an ipsilateral breast event after BCS without RT. Nevertheless, the possibility that these tools are useful to identify patients not typically offered RT who are at higher risk than their CP factors estimate or to identify patients typically offered RT who may be safely observed is appealing. Prospective trials will be needed to confirm how RS segregates from clusters of standard CP factors.

While researchers have examined the correlations among CP factors and RSs, they have yet to report data assessing the range of scores within each subgroup that would typically be considered indicative of low or high risk of LR. From a chemotherapy perspective, $40 \%$ of the patients in our cohort had intermediate RSs ranging from 18 to 30; this group expanded to 69\% with the use of TAILORx risk grouping, reflecting the high proportion of intermediate-risk clinical scenarios. Given the overlap between IBTR risk estimates based on CP factors and RS, our cohort also represents a clinically ambiguous group from an LR standpoint. Although IBTR! score did not correlate with RS in our study, the large variations in RS and IBTR! score suggest that these factors provide different information regarding the risk of IBTR. Interestingly, Ki-67 expression correlated with both RS and IBTR! score. Although Ki-67 expression is part of the RS calculation, it is not part of the IBTR! score calculation. This implies that cellular proliferation may represent a genetic driver of LR.

The present study demonstrates that breast cancer patients who are typically offered the 21-gene RS testing are clinically, pathologically, and perhaps molecularly heterogeneous. We included patients given treatment with various modalities, including BCS, BCT, mastectomy alone, and mastectomy with PORT. As further research is conducted, evaluating the risk of $L R$ in homogeneously treated populations will be important, as the risk factors driving relapse after BCS or mastectomy may be different from those after BCT or PMRT. Neoadjuvant systemic therapy is yet another consideration when evaluating the molecular drivers of LR. Additionally, although researchers have suggested that LR and DR are linked, CP factors and molecular profiles associated with LR may differ from those that predict DR. For instance, Solin et al. (Solin et al. 2013) modified the constituent gene profile for the DCIS RS to better reflect known biological differences between invasive and in situ disease. More comprehensive genetic analyses may define additional or alternative genes that better predict LR than does the 21-gene RS assay used in this study.

Although exploratory in nature, our study has several limitations, including those inherent to retrospective studies. IBTR risk estimation using IBTR! is intended for the breast-conserved population, but we applied this analysis to patients who underwent either breast conserving surgery (BCS) or mastectomy. However, our 
Shaker et al. SpringerPlus

Page 6 of 10

(A)

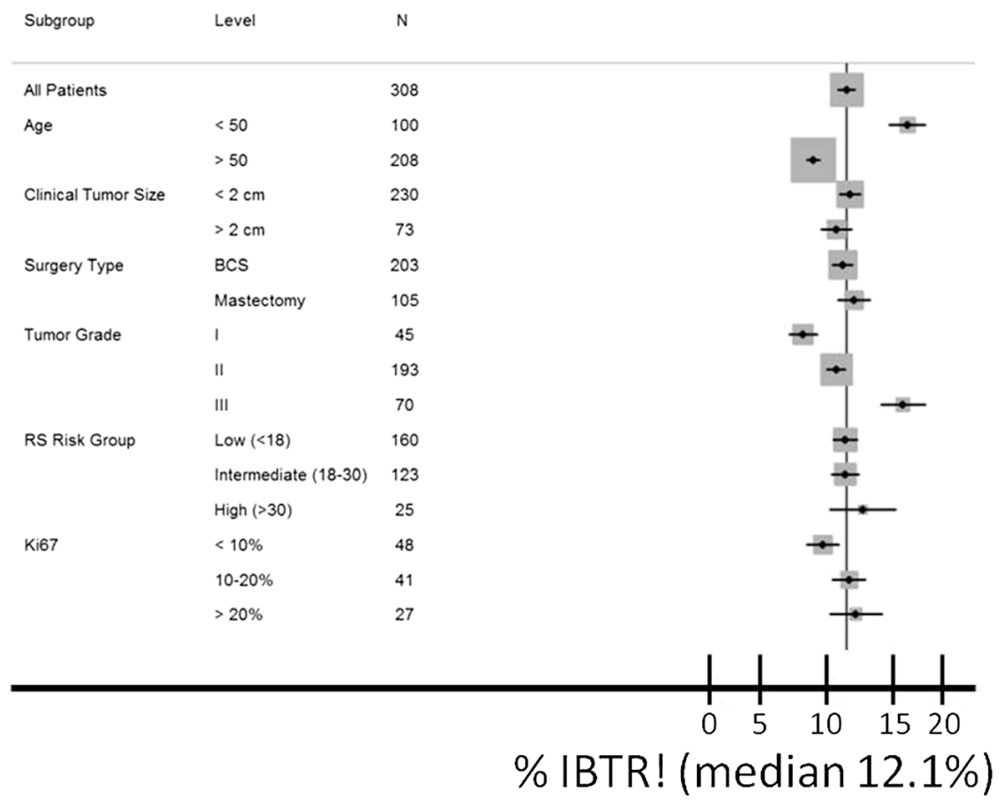

(B)

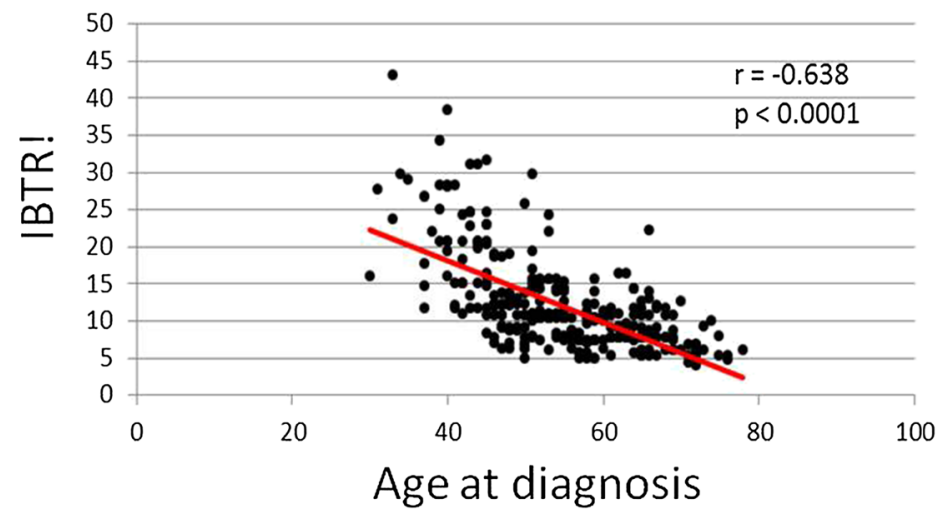

Figure 1 IBTR! score according to patient and tumor characteristics. (A) IBTR! stratified according to age, tumor size, surgery type, tumor grade, RS risk group, and Ki-67 expression. (B) IBTR! according to age at diagnosis.

(A)

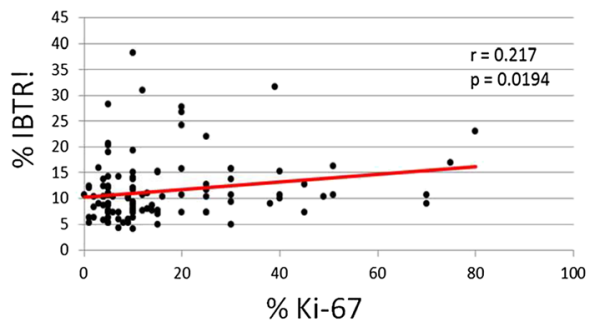

(B)

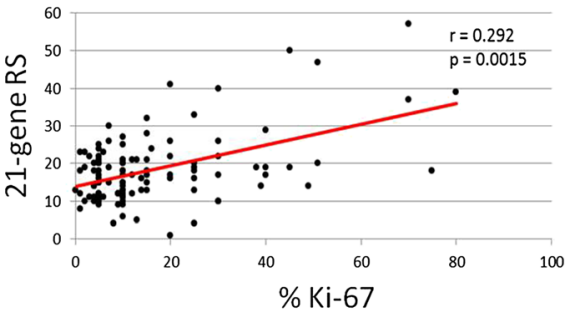

Figure 2 Correlation of Ki-67 expression with (A) IBTR! score and (B) RS. 


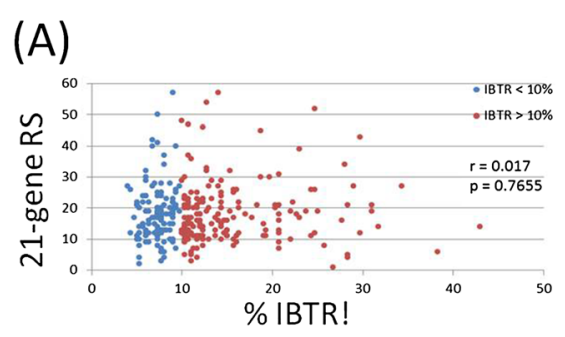

(B)

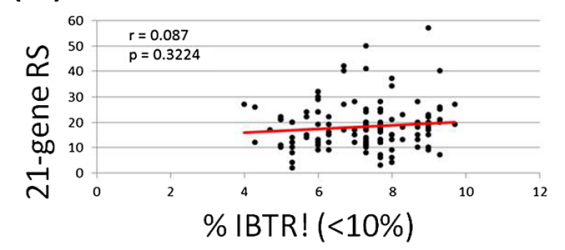

(D)

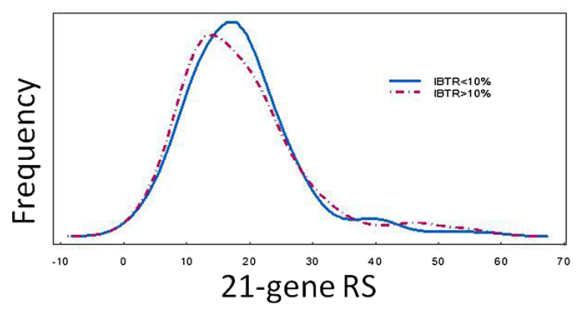

(E)

(C)
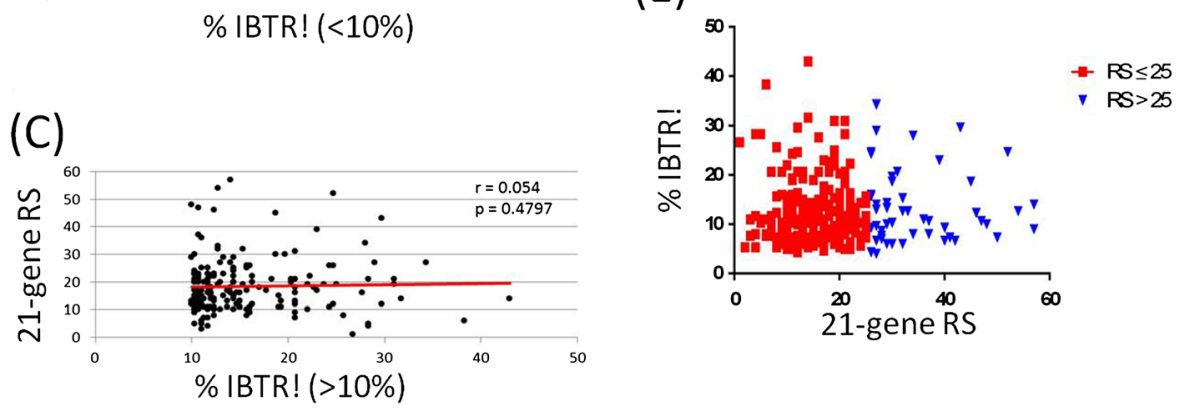

Figure 3 Comparisons of the IBTR! score according to the 21-gene RS. (A) The 21-gene RS versus estimated IBTR! score according to CP factors. (B and C) The 21-gene RS versus IBTR! when the IBTR! was (B) less than 10\% and (C) greater than 10\%. (D) The frequency distribution of IBTR! score according to 21-gene RS. (E) Scatter plot of the large variations in IBTR! in the TAILORx risk groups.

objective was to model the risk for IBTR based on CP factors rather than the actual treatment received. The overall non-significant differences between the two treatment cohorts also suggests that we could indeed isolate and compare IBTR! based upon the CP factors alone. Furthermore, researchers have suggested that IBTR! overestimates the risk of IBTR in high-risk patients. We also could not account for factors other than those used in the IBTR! nomogram, as we did not examine actuarial event rate data. Importantly, IBTR! does not incorporate hormone receptor or HER2 status, and recent studies have suggested that receptor status can influence IBTR (Arvold et al. 2011).
(A)

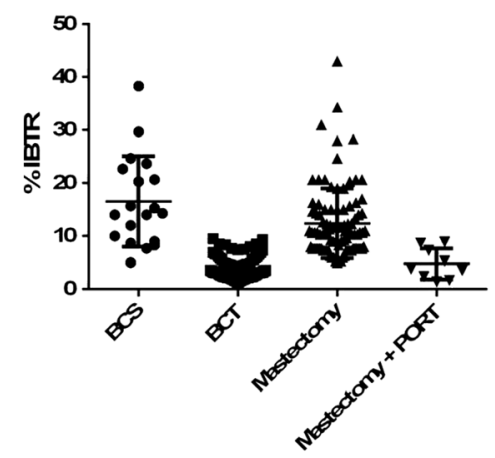

(B)

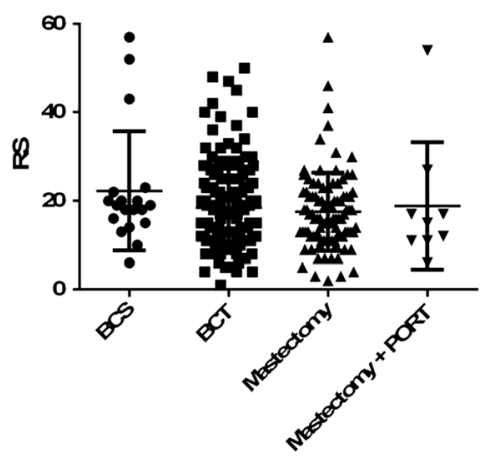

Figure 4 IBTR! and the 21-gene RS according to actual treatments received. (A) IBTR! score according to actual treatment (i.e., adjuvant RT). (B) RS according to actual treatment (i.e., adjuvant RT). The distribution in BCS and mastectomy subgroups are wide in both the IBTR! and RS stratifications. However, the deviation is less in the groups that have undergone RT. BCS, breast conservation surgery; BCT, breast conservation therapy; PORT, post-operative radiation therapy. 
Table 2 Summary of studies assessing the relationship of the RS and LR in breast cancer

\begin{tabular}{|c|c|c|c|c|c|}
\hline Study & $\begin{array}{l}\text { Molecular } \\
\text { profiling tool }\end{array}$ & Population & Objective & $\begin{array}{l}\text { Number of patients in } \\
\text { the study }\end{array}$ & Outcomes and conclusions \\
\hline Thaker et al. (present study) & 21-gene RS assay & $\begin{array}{l}\text { Early-stage, HR-positive, lymph } \\
\text { node-negative }\end{array}$ & $\begin{array}{l}\text { Correlation between } \\
\text { 21-gene RS and IBTR! } \\
\text { nomogram }\end{array}$ & 308 & $\begin{array}{l}\text { No correlation between 21-gene } \\
\text { RS and IBTR! estimates; RS may } \\
\text { complement traditional CP factors } \\
\text { when assessing risk of IBTR in } \\
\text { intermediate-risk patients }\end{array}$ \\
\hline Mamounas et al. & 21-gene RS assay & $\begin{array}{l}\text { Tamoxifen-treated, node-negative, } \\
\text { ER-positive disease treated with } \\
\text { placebo, tamoxifen, or chemotherapy } \\
\text { plus tamoxifen from two NSABP trials } \\
\text { (B-14 and B-20) }\end{array}$ & $\begin{array}{l}\text { Association between RS } \\
\text { and risk of } L R\end{array}$ & $\begin{array}{l}895 \text { tamoxifen-treated, } \\
355 \text { placebo-treated, } \\
424 \text { chemotherapy plus } \\
\text { tamoxifen-treated }\end{array}$ & $\begin{array}{l}\text { Significant association between RS } \\
\text { and risk for } L R ; \text {; R was significantly } \\
\text { associated with RS risk group in } \\
\text { tamoxifen-treated, placebo-treated, } \\
\text { and chemotherapy- plus } \\
\text { tamoxifen-treated patients; RS was } \\
\text { an independent significant predictor } \\
\text { of } L R \text { along with age and type of initial } \\
\text { treatment }\end{array}$ \\
\hline Solin et al. & 21-gene RS assay & $\begin{array}{l}\text { Operable breast adenocarcinoma } \\
\text { with either } 1-3 \text { axillary lymph nodes } \\
\text { involved or negative axillary lymph } \\
\text { nodes with a primary tumor size }>1 \mathrm{~cm} ; \\
\text { patients with HR-positive tumors received } \\
\text { adjuvant hormonal therapy; patients } \\
\text { received AC versus AT chemotherapy as } \\
\text { per ECOG E2197 }\end{array}$ & $\begin{array}{l}\text { Evaluation of the } \\
\text { significance of the } \\
21 \text {-gene RS and biological } \\
\text { subtype relative to LR } \\
\text { after BCT }\end{array}$ & 388 & $\begin{array}{l}\text { Neither biological subtype nor } 21 \text {-gene } \\
\text { RS was associated with LR; for HR-positive } \\
\text { tumors, the } 21 \text {-gene RS evaluated as a } \\
\text { continuous variable was significant for LR; } \\
\text { neither biological subtype nor } 21 \text {-gene RS } \\
\text { should preclude BCT with RT }\end{array}$ \\
\hline Mamounas et al. & 21-gene RS assay & $\begin{array}{l}\text { ER-positive, tamoxifen-treated, } \\
\text { node-positive disease treated } \\
\text { with adjuvant chemotherapy with } \\
\text { AC versus AC-T in the NSABP } \\
\text { B- } 28 \text { trial }\end{array}$ & $\begin{array}{l}\text { Association between } R S \\
\text { and risk of } L R\end{array}$ & 1065 & $\begin{array}{l}\text { RS was significantly associated with LR } \\
\text { after lumpectomy and breast RT and } \\
\text { after mastectomy (no RT) as well as in } \\
\text { patients with } \geq 4 \text { positive nodes (with a } \\
\text { nonsignificant trend in patients with 1-3 } \\
\text { positive nodes); in MVA, RS, nodal status, } \\
\text { and tumor size were all independent } \\
\text { predictors of LR }\end{array}$ \\
\hline Solin et al. & DCIS RS assay & $\begin{array}{l}\text { DCIS treated with surgical excision } \\
\text { without RT in the ECOG E5194 study }\end{array}$ & $\begin{array}{l}\text { Association of DCIS score } \\
\text { (modified RS assay with } 7 \\
\text { cancer-related genes and } \\
5 \text { reference genes) with } \\
\text { risk of IBE }\end{array}$ & 327 & $\begin{array}{l}\text { Continuous DCIS score was significantly } \\
\text { associated with the risk of an IBE and } \\
\text { invasive IBE; this score complements } \\
\text { traditional CP factors }\end{array}$ \\
\hline
\end{tabular}

Abbreviations: NSABP National Surgical Adjuvant Breast and Bowel Project, $A C$ doxorubicin plus cyclophosphamide, $A T$ doxorubicin plus docetaxel, ECOG Eastern Cooperative Oncology Group, $A C-T$ AC followed by paclitaxel, MVA multivariate analyis, IBE ipsilateral breast event (defined as local recurrence of DCIS or invasive carcinoma), LR locoregional recurrence. 
Additionally, the IBTR! nomogram reports a point estimate of the risk of IBTR at 10-years, so continuous risk estimates before and after 10-years were not evaluable. Furthermore, our cohort comprised an overall favorable group of patients with node-negative disease. Consistent with previously published studies, (Paik et al. 2004; Mamounas et al. 2010; Solin et al. 2012; Mamounas et al. 2013) the actuarial event rates in such patients are low, requiring large patient cohorts with long follow-up durations for examination of actual outcomes. According to these data, we hypothesize that RSs may vary similarly in patients with node-positive breast cancer, for whom the decision to add a supraclavicular field to BCT or give postmastectomy radiation therapy (PMRT) may be most influenced by the addition of an independent factor that correlates with LR. However, our cohort did not have node-positive disease, and this relationship remains to be explicitly shown.

Despite these drawbacks, molecular profiling for LR continues to rapidly evolve. RS groups and their risks of IBTR are largely heterogeneous, and discordant RS values may provide information beyond that provided by standard $\mathrm{CP}$ factors. Indeed, integrating the RS with traditional $\mathrm{CP}$ parameters, treatment type, and patientrelated factors may improve estimation of the risk of LR over use of any of these factors alone. Goldstein et al. and Tang et al. reported that combining the RS with traditional CP factors can improve prognosis for DR, (Goldstein et al. 2008; Tang et al. 2011) and such a clinical integrator may be an important new tool for estimating LR risk. The PAM-50 assay (Nanostring Prosigna assay) integrates clinical and molecular prognostic models to estimate the risk of later recurrence in postmenopasual, HR-positive breast cancer patients and is now commercially available. Future research efforts will require prospective assessment of these factors in large data sets to confirm, validate, and even integrate molecular signatures with $\mathrm{CP}$ factors in intermediate-risk patients. These data will help establish the number of patients with intermediate- and high-RS in low-risk subgroups required to screen in clinical trials, ultimately leading to personalization of treatment and improved outcomes.

\section{Competing interests}

Dr. Benjamin Smith has research funding from Varian Medical Systems. Dr. Simona Shaitelman has research funding from Elekta and serves as a consultant for the MD Anderson Physician's Network. Other authors declare that they have no conflict of interest.

\section{Authors' contributions}

WAW, NGT, KEH designed the study. LP, WAW, TAB, LH contributed data. WAW, NGT, KEH, MCS, MFM, BDS, WT, SFS, LP, TAB, EAS, GHP participated in drafting and editing the manuscript. MFM lead the data analysis. MFM, LH, WAW, NGT, TAB participated in data interpretation. All authors read and approved the final manuscript.

\section{Acknowledgements}

We thank Donald Norwood of the Department of Scientific Publications at The University of Texas MD Anderson Cancer Center for his assistance in editing this manuscript.

Funding

Supported by the $\mathrm{NIH/NCI}$ under award number P30CA016672.

\section{Author details}

'Department of Radiation Oncology, Unit 1202, The University of Texas MD Anderson Cancer Center, 1515 Holcombe Boulevard, Houston, TX 77030, USA. ${ }^{2}$ Department of Pathology, The University of Texas MD Anderson Cancer Center, Houston, TX, USA. ${ }^{3}$ Department of Biostatistics, The University of Texas MD Anderson Cancer Center, Houston, TX, USA. ${ }^{4}$ Department of Medical Oncology, Yale Cancer Center, New Haven, CT, USA.

Received: 11 December 2014 Accepted: 20 January 2015

Published online: 30 January 2015

\section{References}

Arvold ND, Taghian AG, Niemierko A, Abi Raad RF, Sreedhara M, Nguyen PL, Bellon JR, Wong JS, Smith BL, Harris JR (2011) Age, breast cancer subtype approximation, and local recurrence after breast-conserving therapy. J Clin Oncol 29(29):3885-3891, doi:10.1200/JCO.2011.36.1105

Cheng SH, Horng CF, West M, Huang E, Pittman J, Tsou MH, Dressman H, Chen CM, Tsai SY, Jian JJ, Liu MC, Nevins JR, Huang AT (2006) Genomic prediction of locoregional recurrence after mastectomy in breast cancer. J Clin Oncol 24(28):4594-4602, doi:10.1200/JCO.2005.02.5676

Delpech Y, Wu Y, Hess KR, Hsu L, Ayers M, Natowicz R, Coutant C, Rouzier R, Barranger E, Hortobagyi GN, Mauro D, Pusztai L (2012) Ki67 expression in the primary tumor predicts for clinical benefit and time to progression on first-line endocrine therapy in estrogen receptor-positive metastatic breast cancer. Breast Cancer Res Treat 135(2):619-627, doi:10.1007/s10549-012-2194-2

Goldstein L, Gray R, Badve S, Childs BH, Yoshizawa C, Rowley S, Shak S, Baehner FL, Ravdin PM, Davidson NE, Sledge GW Jr, Perez EA, Shulman LN, Martino S, Sparano JA (2008) Prognostic utility of the 21-gene assay in hormone receptor-positive operable breast cancer compared with classical clinicopathologic features. J Clin Oncol 26(25):4063-4071, doi:10.1200/ jco.2007.14.4501

Haffty BG (2002) Molecular and genetic markers in the local-regional management of breast cancer. Semin Radiat Oncol 12(4):329-340, doi:10.1053/srao.2002.35252

Harris L, Fritsche H, Mennel R, Norton L, Ravdin P, Taube S, Somerfield MR, Hayes DF, Bast RC Jr, American Society of Clinical O (2007) American Society of Clinical Oncology 2007 update of recommendations for the use of tumor markers in breast cancer. J Clin Oncol 25(33):5287-5312, doi:10.1200/JCO.2007.14.2364

Hormone therapy with or without combination chemotherapy in treating women who have undergone surgery for node-negative breast cancer (The TAILORx Trial). (2013). http://cancer.gov/clinicaltrials/search/view? cdrid=472066\&version=healthprofessional. Accessed 6/28/13 2013

IBTR! Version 2.0 Breast Cancer Model. https://www.tuftsmedicalcenter.org/ibtr/.

Kilickap S, Kaya Y, Yucel B, Tuncer E, Babacan NA, Elagoz S (2014) Higher Ki67 expression is associates with unfavorable prognostic factors and shorter survival in breast cancer. Asian Pac J Cancer Prev 15(3):1381-1385

Kirk R (2010) Risk factors. Oncotype DX assay predicts local recurrence in breast cancer. Nat Rev. Clin Oncol 7(6):300, doi:10.1038/nrclinonc.2010.75

Mamounas EP, Tang G, Fisher B, Paik S, Shak S, Costantino JP, Watson D, Geyer CE Jr, Wickerham DL, Wolmark N (2010) Association between the 21-gene recurrence score assay and risk of locoregional recurrence in node-negative, estrogen receptor-positive breast cancer: results from NSABP B-14 and NSABP B-20. J Clin Oncol 28(10):1677-1683, doi:10.1200/JCO.2009.23.7610

Mamounas E, Tang G, Paik S, Baehner E, Liu Q, Jeong J, Kim S, Butler S, Jamshidian F, Cherbavaz DB, Sing A, Shak S, Julian T, Lembersky B, Wickerham D, Costantino J, Wolmark N The 21-gene Recurrence Score (RS) Predicts Risk of Loco-regional Recurrence (LRR) in Node (+), ER (+) Breast Cancer (BC) After Adjuvant Chemotherapy and Tamoxifen: Results from NSABP B-28. In: Society of Surgical Oncology 66th Annual Cancer Symposium, National Harbor, Maryland, 2013. vol 1. Annals of Surgical Oncology, p S6

Network NCC (2013) NCCN Clinical Practice Guidelines in Oncology (NCCN Guidelines) Breast Cancer. Version 2.2013. http://www.nccn.org/professionals/ physician_gls/pdf/breast.pdf. 
Nuyten DS, Kreike B, Hart AA, Chi JT, Sneddon JB, Wessels LF, Peterse HJ, Bartelink H, Brown PO, Chang HY, van de Vijver MJ (2006) Predicting a local recurrence after breast-conserving therapy by gene expression profiling. Breast Cancer Res 8(5):R62, doi:10.1186/bcr1614

Paik S, Shak S, Tang G, Kim C, Baker J, Cronin M, Baehner FL, Walker MG, Watson D, Park T, Hiller W, Fisher ER, Wickerham DL, Bryant J, Wolmark N (2004) A multigene assay to predict recurrence of tamoxifen-treated, node-negative breast cancer. N Engl J Med 351(27):2817-2826, doi:10.1056/NEJMoa041588

Paik S, Tang G, Shak S, Kim C, Baker J, Kim W, Cronin M, Baehner FL, Watson D, Bryant J, Costantino JP, Geyer CE Jr, Wickerham DL, Wolmark N (2006) Gene expression and benefit of chemotherapy in women with node-negative, estrogen receptor-positive breast cancer. J Clin Oncol 24(23):3726-3734, doi:10.1200/JCO.2005.04.7985

Sanghani M, Balk E, Cady B, Wazer D (2007) Predicting the risk of local recurrence in patients with breast cancer: an approach to a new computer-based predictive tool. Am J Clin Oncol 30(5):473-480, doi:10.1097/COC.0b013e31805c13d9

Sanghani M, Truong PT, Raad RA, Niemierko A, Lesperance M, Olivotto IA, Wazer DE, Taghian AG (2010) Validation of a web-based predictive nomogram for ipsilateral breast tumor recurrence after breast conserving therapy. J Clin Oncol 28(5):718-722, doi:10.1200/jco.2009.22.6662

Solin L, Gray R, Goldstein L, Recht A, Baehner FL, Shak S, Badve S, Perez EA, Shulman LN, Martino S, Davidson NE, Sledge GW Jr, Sparano JA (2012) Prognostic value of biologic subtype and the 21-gene recurrence score relative to local recurrence after breast conservation treatment with radiation for early stage breast carcinoma: results from the Eastern Cooperative Oncology Group E2197 study. Breast Cancer Res Treat 134(2):683-692, doi:10.1007/s10549-012-2072-y

Solin L, Gray R, Baehner FL, Butler SM, Hughes LL, Yoshizawa C, Cherbavaz DB, Shak S, Page DL, Sledge GW Jr, Davidson NE, Ingle JN, Perez EA, Wood WC, Sparano JA, Badve S (2013) A multigene expression assay to predict local recurrence risk for ductal carcinoma in situ of the breast. J Natl Cancer Inst 105(10):701-710, doi:10.1093/jnci/djt067

Taghian A, Jeong JH, Mamounas E, Anderson S, Bryant J, Deutsch M, Wolmark N (2004) Patterns of locoregional failure in patients with operable breast cancer treated by mastectomy and adjuvant chemotherapy with or without tamoxifen and without radiotherapy: results from five National Surgical Adjuvant Breast and Bowel Project randomized clinical trials. J Clin Oncol 22(21):4247-4254, doi:10.1200/JCO.2004.01.042

Tang G, Cuzick J, Costantino JP, Dowsett M, Forbes JF, Crager M, Mamounas EP, Shak S, Wolmark N (2011) Risk of recurrence and chemotherapy benefit for patients with node-negative, estrogen receptor-positive breast cancer: recurrence score alone and integrated with pathologic and clinical factors. J Clin Oncol 29(33):4365-4372, doi:10.1200/JCO.2011.35.3714

Voduc KD, Cheang MC, Tyldesley S, Gelmon K, Nielsen TO, Kennecke H (2010) Breast cancer subtypes and the risk of local and regional relapse. J Clin Oncol 28(10):1684-1691, doi:10.1200/JCO.2009.24.9284

Wapnir IL, Aebi S, Gelber S, Anderson SJ, Lang I, Robidoux A, Mamounas EP, Wolmark N (2008) Progress on BIG 1-02/IBCSG 27-02/NSABP B-37, a prospective randomized trial evaluating chemotherapy after local therapy for isolated locoregional recurrences of breast cancer. Ann Surg Oncol 15(11):3227-3231, doi:10.1245/s10434-008-0129-2

\section{Submit your manuscript to a SpringerOpen ${ }^{\circ}$ journal and benefit from:}

- Convenient online submission

Rigorous peer review

- Immediate publication on acceptance

- Open access: articles freely available online

- High visibility within the field

- Retaining the copyright to your article

Submit your next manuscript at $\gg$ springeropen.com 